\title{
Half of patients in intensive care receive suboptimal care
}

\author{
Zosia Kmietowicz London
}

Consultants need to be more available to supervise emergency medical admissions to improve the care of acutely sick patients, recommends a report.

A study by the charity the National Confidential Enquiry into Patient Outcome and Death (NCEPOD) shows that a quarter of patients who were admitted to intensive care units in England and Wales in one month in 2003 died. Nearly half of these patients received care that was judged to be less than good practice. And deficiencies in care in a third of the admitted patients may have contributed to their death, it says.

The charity aims to maintain and improve medical and surgical care. Its report covered all 1677 patients who were admitted to intensive care units in hospitals in England and Wales in June 2003. Of these patients 560 died, and 439 of the deaths were investigated fully by the charity.

In general, senior house officers were left in charge of caring for severely ill patients, especially in the evening and at night-the busiest time for new admissions to intensive care units, the study shows. In nearly 6 in 10 cases consultants had no knowledge or input into the referral, and one in four patients had to wait for more than 12 hours before being seen by a consultant.

"Patients should rarely be admitted to ICU [intensive care units] without the prior knowledge or involvement of a consultant intensivist," the report says.

Creating new acute physician posts may help in the long term to improve the care of patients who need intensive care, says the report. But in the short term consultants' job plans should reflect the pattern of demand for emergency admissions, especially at the busiest times in the evenings and at night, it recommends. "Provision should be made for planned consultant

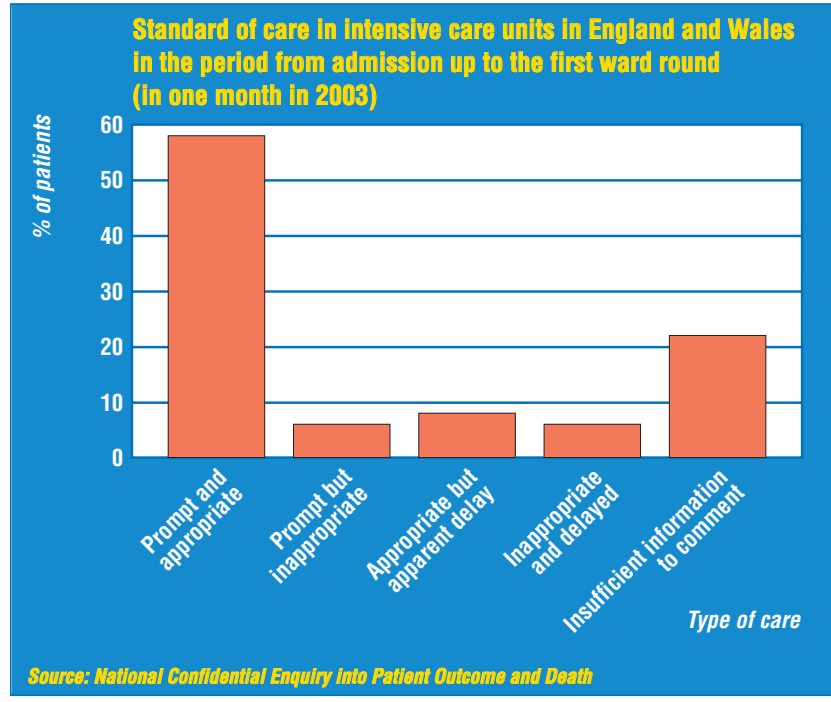

presence in the evenings (and perhaps at night in busier units)," it says.

The report also calls for better training for junior doctors in how to recognise critical illness and the role of fluid and oxygen treatment in managing emergency patients. It adds that consultants should supervise junior doctors more closely.

An Acute Problem? can be seen at www.ncepod.org.uk

\section{Merck chief quits as further material on Vioxx emerges}

\section{Ray Moynihan Sydney}

The chief executive officer and chairman of Merck, Raymond Gilmartin, resigned unexpectedly last week, the same day a damning US Congress report on the company was released.

Even though Mr Gilmartin stepped down hurriedly a year ahead of schedule, Merck's official position is that the resignation was not connected to the growing global controversy over its anti-arthritis drug rofecoxib (Vioxx), which was withdrawn from the market late last year, after studies produced evidence linking it to heart problems (BMJ 2004;329:816).
He will be replaced by the company's current head of manufacturing, Richard Clark. "Dick is a great choice to become the next chief executive officer,' said Mr Gilmartin, in Merck's prepared statement about his resignation. "He has successfully led many of the company's most important strategic initiatives."

At the same time as $\mathrm{Mr}$ Gilmartin was resigning, a leading Democrat member of the US Congress's Government Reform Committee, at the start of a Congressional hearing looking into "the roles of FDA and pharmaceutical companies in ensuring the safety of approved drugs, like Vioxx," released a scathing critique of the strategies Merck had used to market rofecoxib. In response to a request from the committee the company released more than 20000 pages of internal documents and promotional memos, including course curriculums, training manuals, and talking points for its sales force (http://democrats.reform.house gov/story.asp?ID=848).

"Based on a review of the Merck documents," wrote the high profile Congressional representative Henry Waxman, "it appears that Merck sent over 3000 highly trained representatives into doctors' offices and hospitals armed with misleading information about Vioxx's health risks."

According to Mr Waxman's analysis, the Merck documents show that the company's sales force was urged to persuade doctors that rofecoxib was safer than other anti-inflammatory drugs, at a time when scientific studies were indicating the contrary. Drug representatives were apparently prohibited from discussing studies with contrary findings.

The Washington Post reports Dennis Erb, Merck's vice president for global regulatory development, as saying the company's actions were timely and appropriate and that staff were trained to be "accurate and balanced" in presenting information. "We believe Merck acted appropriately and responsibly," he said (www.washingtonpost.com, 6 May 2005).

Longer versions of these articles are on bmj.com 